\title{
FIM DO CONSENSO: A POLÍTICA EXTERNA BRASILEIRA NO SÉCULO XXI
}

\author{
Juliano dos Santos Bravo ${ }^{1}$
}

\section{Resumo}

Da política externa brasileira do governo Fernando Henrique Cardoso (1995-2002) à gestão atual, marcada pela consolidação do impeachment da presidenta Dilma Rousseff em agosto de 2016, pode ser vislumbrada como um arco de ascensão, consolidação e declínio. Entendemos que a ascensão e a consolidação foram possíveis devido a um consenso político interno em volta do presidencialismo de coalizão que produziu estabilidade, além, evidentemente, de inúmeros fatores internos e externos que são apreciados aqui de forma adjacente. A partir da eleição de Dilma Rousseff para o segundo mandato esse consenso foi desfeito. A 'guerra' política ficou amplamente aberta. Portanto, o objetivo central do artigo é visualizar esse arco da ascensão ao declínio para, dessa maneira, obter ferramentas analíticas capazes de identificar as primeiras marcas e desafios do governo atual, especialmente no que tange as capacidades de autonomia e desenvolvimento nacionais. Para tanto, o texto procura se auxiliar dos conceitos de autonomia e desenvolvimento produzidos e entendidos por grandes pesquisadores da área. Por fim, frisa-se esta linha argumentativa e analítica do texto: conceitos ou valores entendidos como fundamentais e constantes na política externa brasileira; características gerais e essenciais da política externa de FHC, Lula e Dilma; e o delineamento da política externa atual, bem como seus desafios.

Palavras-chave:Política Externa. Política Externa brasileira contemporânea. Autonomia. Desenvolvimento.

\begin{abstract}
From the Brazilian foreign policy of the Fernando Henrique Cardoso administration (1995-2002) to the current management, stemming from the consolidation of President Dilma Rousseff's impeachment in August 2016, can be seen as an arc of ascension, consolidation and decline.We understand that ascension and consolidation were possible because of an internal political consensus around coalition presidentialism that produced stability, and of course, innumerable internal and external factors that are appreciated here in an adjacent way.From the election of Dilma Rousseff to the second term this consensus was broken.The political 'war' was largely open.Therefore,
\end{abstract}

${ }^{1}$ Mestrando em Ciências Sociais, PUC/RS, email: julianobrav022@gmail.com . 
79 | InterAção

the central objective of the article is to visualize this arc from the rise to the decline, in order to obtain analytical tools capable of identifying the first marks and challenges of the current government, especially with regard to national autonomy and development capacities.To do so, the text seeks to aid the concepts of autonomy and development produced and understood by large researchers in the area.Finally, this argumentative and analytical line of the text is highlighted: concepts or values understood as fundamental and constant in Brazilian foreign policy; General and essential characteristics of FHC's foreign policy, Lula and Dilma; And the design of the current foreign policy, as well as its challenges.

Keywords:Foreign Policy. Contemporary Brazilian foreign policy.Autonomy. Development.

\section{INTRODUÇÃO}

A atual configuração política e econômica brasileira requer um repensar de sua trajetória nas últimas décadas, através de vários aspectos que influenciaram a crise pela qual o país passa, para melhor entender o quadro geral e projetar visões analíticas sobre os próximos anos. O mesmo exercício passa pela esfera da política externa brasileira (PEB), palco de grandes transformações. Desde os conceitos formados a partir da construção histórica e constante da atuação externa brasileira aos paradigmas estratégicos da mesma; desde as aproximações em torno de um consenso político que propiciou estabilidade e promoção contínua de autonomia e desenvolvimento ao ocaso do presidencialismo de coalisão, declínio na inserção internacional e crise políticaeconômica-institucional aguda.

Estes são, por si sós, temas deveras relevantes e extensos, razão pela qual a vigente pesquisa não pretende, como qualquer pesquisa não deva pretender, findar o debate e tampouco considerar respostas definitivas para questões tão densas. 
80 | InterAção

A política externa brasileira detém um saldo histórico de grande valia, possuindo conceitos que a acompanham desde a formação da República ou mesmo antes. Neste caso, nos usufruiremos da ideia de autonomia e de desenvolvimento como pertencente a esse rol de conceitos ou valores que permeiam a inserção externa brasileira ao longo do tempo, além de suscitarmos algumas outras contribuições importantes para o campo de estudo. Para tanto, o segundo tópico está encarregado de promover esse debate acerca da autonomia e do desenvolvimento enquanto traços gerais e contínuos na PEB, apresentando alguns dos principais pensadores da área. Salienta-se que o objetivo central do trabalho não está vinculado a uma profunda análise dos referidos conceitos, mas apresentá-los como base conceitual para a articulação argumentativa.

O consenso político que contribuiu para a estabilidade política e econômica brasileira, influindo positivamente na promoção das capacidades nacionais no meio internacional, chegou ao fim e ao cabo culminando com o impeachment da presidenta Dilma Rousseff em agosto de 2016. Nesse sentido, o texto procura elucidar as principais características da política externa do presidente Fernando Henrique Cardoso (1995-2002) e Luís Inácio 'Lula' da Silva (2003-2010), bem como suas aproximações e distanciamentos, para formar a linha argumentativa que alcança a gestão Rousseff (2011-2016), o próprio impeachment e o novo governo, ainda em exercício, de Michel Temer.

Os objetivos traçados capacitam à formação de um conciso arcabouço capaz de ilustrar o estado de coisas que se encontra a política externa brasileira, suas potencialidades e seus desafios em continuar promovendo a autonomia e o desenvolvimento nacionais. Além disso, expressar as primeiras impressões da atuação externa do governo oriundo do impeachment, com suas significantes idiossincrasias e baixa legitimidade. 
81 InterAção

\section{POLÍTICA EXTERNA BRASILEIRA: ESCOPO CONCEITUAL E PROCEDIMENTAL}

A política externa de um Estado expressa a execução racional de uma estratégia preestabelecida levando em conta fatores internos de ordem histórica, social, econômica e política. Representa, ou deve representar, a projeção nacional no meio internacional por meio de seus atores e da própria sociedade, procurando coadunar os interesses domésticos com as implicações do próprio sistema internacional anárquico. Dada essas breves características, o Estado deve prover, primeiro, a própria segurança, a própria sobrevivência, tendo em vista os aspectos sistêmicos sólidos, segundo, suscitar acréscimo de poder nacional capaz de o alavancar no cenário internacional, prosperando desenvolvimento e autonomia frente as implicações e imprevisibilidades das relações internacionais.

No caso brasileiro, os atributos principais de inserção internacional de uma nação podem ser muito bem apreciados nesse sentido. Como desenvolve Miyamoto (2009), “possivelmente não se encontrarão precedentes na política brasileira, em que sua conduta externa não tenha sido em busca de um status mais favorável no contexto das relações globais de poder" (MIYAMOTO, 2009, p. 15). A importância do poder nas relações internacionais é deveras significativo, em favor disso, "países como o Brasil que detêm elementos tradicionais de poder favoráveis - tais como extenso território, população apreciável, recursos naturais e forças armadas razoáveis - sempre têm aspirações" (MIYAMOTO, 2011, p. 8), no mesmo sentido coadunam Peter Hakim (2010, p. 44) e Samuel P. Guimarães (2001, p. 11).

Considerando esses pontos preliminares, o presente tópico busca elucidar os substanciais conceitos e características da atuação internacional do Brasil, os constantes e históricos elementos que marcam o país em sua inserção 
82 InterAção

internacional desde sua consolidação enquanto República e nas últimas décadas. Nesse seguimento, Letícia Pinheiro (2004) compreende que "no plano das ideias, valores e doutrinas que orientam a ação externa do Brasil ao longo do último século destaca-se a busca pela autonomia" (PENHEIRO, 2004, p. 7-8). Por conseguinte, no sentido estruturado na introdução, o esforço de acréscimo de autonomia traduz um dos principais traços do Brasil.

Portanto, a autonomia, em seus amplos sentidos definidos pelos grandes pensadores e formuladores do tema, tem feito parte de uma gama variada e consolidada na análise de política externa brasileira (PEB), tanto no Brasil quanto no exterior. Na corrente pesquisa, o conceito está baseado em (GUIMARÃES, 2001; PINHEIRO, 2000; 2004; VIGEVANI; OLIVEIRA, 2003; VIGEVANI; CEPALUNI, 2007; SARAIVA, M. G., 2013; SARAIVA, J. F. G., 2014; VALENÇA, 2016).

O outro conceito constituinte da análise, mesmo com características menos definidas e mais complementares, também compreendido no arcabouço de Pinheiro (2004), é a ideia do desenvolvimento. Logo, segundo a autora, a inserção internacional do Brasil tem se notabilizado por uma busca constante dos meios internacionais capazes de reverter-se em desenvolvimento interno, ou seja, uma política externa promotora de desenvolvimento nacional, sobretudo econômico, político, militar, tecnológico.

Nas últimas décadas da política externa brasileira é possível averiguar tais fundamentos, também, "nos grandes temas da agenda global, principalmente daqueles assuntos que dizem respeito ao desenvolvimento nacional, relacionados com o meio ambiente, a pobreza, os recursos energéticos e com os protecionismos" (MIYAMOTO, 2011, p. 21). Ambos projetam, tendo em vista esses conceitos preliminares e nosso entendimento, várias vias com objetivo central de acrescer autonomia e desenvolvimento nacionais. Esses 
83 | InterAção

atributos podem bem ser identificados em vários momentos históricos, como nas gestões Vargas (1930-45/ 1951-54), momento em que a política externa "centrava-se como elemento propulsor de desenvolvimento nacional" (AYRES PINTO; BRAVO, 2016, p. 88), conhecido como "projeto varguista de desenvolvimento" (VIZENTINI, 2008, p. 82).

Assim sendo, estabelecemos que a ideia de desenvolvimento como característica constante na política externa brasileira está substancialmente estruturada em (CERVO; BUENO, 2002; FLEMES, 2010a; 2010b; GUIMARÃES, 2001; MIYAMOTO, 2011; PECEQUILO, 2008; PINHEIRO, 2004; PINO, 2012; VIZENTINI, 2005; 2008; 2013).

Como estabelecido, mesmo concisamente, esses dois atributos são formadores e construtores das particularidades identitárias da Política Externa Brasileira. Como sublinha Valença (2016), “a síntese é a busca por autonomia como forma de alcançar e sustentar essa posição de destaque no plano internacional" (VALENÇA, 2016, p. 47). Para atingir esses objetivos a PEB tem se projetado ao longo das últimas décadas a partir de diferentes estratégias, especialmente durante a gestão de Fernando Henrique Cardoso (1995-2002), de Luís Inácio 'Lula' da Silva (2003-2010) e, mesmo que de perfil menos propositivo, de Dilma Rousseff (2011-2016).

Salientamos, ainda, que há outras concepções próximas ou distantes destas em destaque (autonomia e desenvolvimento) produzidas por grandes pesquisadores do campo. É o caso de Brigagão; Rodrigues (2006), que estipulam duas linhas constantes e complementares, quais sejam: a continuidade e a inovação. Tendo a primeira "como base a prevalência do Direito Internacional e os princípios universalistas [...]" (BRIGAGÃO; RODRIGUES, 2006, p. 14). E a segunda, “- com flexibilidade e pragmatismo - em função dos movimentos da 
84 | InterAção

conjuntura internacional, nacional e regional [...]" (BRIGAGÃO; RODRIGUES, 2006, p. 14).

Existem, ainda, duas distintas estratégias de inserção internacional do país, como a concepção institucionalista pragmático e autonomista (SARAIVA, M. G., 2010) Sendo a primeira associada à gestão Fernando H. Cardoso, a segunda às gestões Luís I. 'Lula' da Silva e à Dilma V. Rousseff. Ainda assim é prudente enfatizar que, de acordo com Valença (2016), “ambos os paradigmas são engajados internacionalmente, estimulando a participação mais ativa do Brasil na política internacional por meio de acordos e parcerias que o aproximasse dos centros de poder" (VALENÇA, 2016, p. 48). Isto é, neste caso não são os próprios conceitos historicamente construídos e de aspectos contínuos na PEB, mas estratégias específicas identificadas com um modelo de inserção (PSDB ou PT) que podem ser analisados a luz da busca de autonomia e desenvolvimento, dentro de um consenso doméstico de proximidades. O qual pensamos que chegou ao seu fim a partir da crise política e econômica que colocou em cheque o presidencialismo de coalisão.

De qualquer modo, para além das concepções estruturantes da política externa brasileira (já brevemente organizadas acima), existem dois traços de fundamental importância na presente análise da PEB no século XXI. Estas são compreendidas aqui por meio de Pecequilo (2008): a tendência "hemisféricabilateral e a global-multilateral" (PECEQUILO, 2008, p. 136). Encontra-se do mesmo modo, em Forman; Myers (2016), como um pêndulo oscilante "entre o americanismo e o globalismo" (FORMAN; MYERS, 2016, p. 13). Isto é, a existência de um eixo vertical em que o país se relaciona preferencialmente com os EUA, como símbolo de uma relação tradicional bilateral com o centro de poder (assim como com a Europa, mas sobretudo com os EUA), e um eixo horizontal em que o país busca relações mais simétricas (ou com objetivo de 
85 | InterAção

diminuição de assimetrias de poder) para compensar seu status intermediário atuando em via multilateralismo.

Entretanto, Pecequilo (2008) atenta para o fato de existir uma armadilha dicotômica nessa perspectiva dualista, em particular na PEB dos governos Lula (2003-2010) e Dilma (2011-2016). Pois, a "coadunação dos eixos tem se provado essencial para a recuperação do status como potência média emergente, permitindo revitalizar tradições e encontrar um espaço diferenciado de atuação no reordenamento do pós-Guerra Fria" (PECEQUILO, 2008, p. 150). Assim, conforme a argumentação da autora, a combinação dos eixos horizontais e verticais tem se demonstrado eficientes para o poder de barganha frente às grandes potências, bem como o acréscimo de poder junto aos emergentes e à articulação positiva em nível regional como propositor de liderança consensual. Não obstante, os críticos a essa perspectiva tem se referido de modo negativo, alegando que tal política externa seria "afetiva", "politizada" e "ideológica" (BUENO, 2016; AZAMBUJA, 2016; ALMEIDA, 2014; 2016). Pontos densamente rechaçados em níveis econômicos, geoestratégicos e políticos, em (VELASCO JUNIOR, 2016; GRABENDORFF, 2010; SARAIVA, 2014; PENNAFORTE, 2016).

Ao fim deste tópico e a partir do debate aqui tratado, estabelecemos as seguintes diretrizes em exame ao correr do texto: (1) as principais características da política externa brasileira durante o consenso (1995-2010), especialmente; e (2) o fim do consenso, os traços iniciais da política externa do Governo Temer e as possíveis expectativas. 


\section{POLÍTICA EXTERNA BRASILEIRA DE FHC À TEMER}

O consenso é entendido aqui a partir de uma vinculação de caráter conceitualtanto formada a partir do governo FHC (1995-2002) e continuada e consolidada no governo Lula (2003-2010), quanto oriunda de sustentações históricas ao longo do tempo, em que pese algumas diferenças substanciais na estratégia de inserção internacional dos formuladores dos dois partidos. "Ao passo que os primeiros concebem a política externa como instrumento de adaptação à globalização, os segundos imaginam a diplomacia como instrumento de resistência" (SPEKTOR, 2016, p. 18-19). As diferenças de concepção do cenário e sistema internacionais produziram as distintas interpretações e produção dos modos de inserção.

Além do mais, Matias Spektor (2016) entende que na concepção dos tucanos, se o "Brasil quisesse participar da globalização precisaria de 'credenciais de boa conduta internacional'. Foi isso que a diplomacia de FHC buscou em áreas como direitos humanos, não proliferação nuclear, meio ambiente e comércio internacional" (SPEKTOR, 2016, p. 19). Já "na concepção petista, o Brasil deveria explorar as rachaduras do projeto da globalização, que eram evidentes nos protestos de Seattle (1999) e foram escancaradas quando o governo americano invadiu o Iraque sem autorização das Nações Unidas (SPEKTOR, 2016, p. 20).

Nesse seguimento, identificaremos as diferenças entre as políticas externas para, então, proceder no reconhecimento das similitudes e, assim, entender o consenso para, por fim, analisar o rompimento desse e constatar as primeiras impressões do governo pós-impeachment da Presidenta Dilma Rousseff. Por meio dessa forma, a analise pode reconhecer os avanços e os 
87 | InterAção

retrocessos, bem como os desafios impostos ao acréscimo da autonomia e do desenvolvimento nacionais via política externa.

\subsection{A POLÍTICA EXTERNA DO GOVERNO FHC (1995-2002) E LULA (2003-2010), DISTANCIAMENTOS E APROXIMAÇÕES}

A política externa do governo $\mathrm{FHC}$, partindo diretamente para os aspectos centrais de elucidação do texto, pode ser caracterizada concisamente pelo seguinte perfil, conforme Vizentini (2013):

- Avançar no caminho da integração regional aprofundando o Mercosul;

- Estimular a estratégia de diversificação de parceiros nas relações bilaterais;

- Insistir junto às organizações econômicas multilaterais, em particular a OMC, no ideal de multilateralismo, sempre sustentado pelo país;

- Concentrar esforço para elevar a condição de potência internacional do Brasil, tornando-se membro permanente no Conselho de Segurança da ONU [...] (VISENTINI, 2013, p. 104).

Esses traços gerais do período suscitam, conforme Letícia Pinheiro (2004), um novo caminho paradigmático para a inserção internacional do Brasil. Sublinha-se, a título de elucidação, a diferença entre paradigma de inserção externa e conceitos e valores tradicionais construídos historicamente. Nesse sentido, consoante Pinheiro (2004):

[...] o governo FHC foi marcado pela intenção de influenciar o desenho da nova ordem internacional, intensificando a participação brasileira nos diversos foros decisórios multilaterais como a ONU e a OMC. [...] Nas palavras do ministro Luiz Felipe Lampreia (1995-2000), tratou-se da construção de um novo paradigma de política externa, por ele chamado de paradigma pela integração (PINHEIRO, 2004, p. 61). 
Se por um lado, o ministro Lampreia procurou nomear a PEB da época como paradigma pela integração, Pinheiro (2004), por seu turno, vislumbrou como institucionalismo pragmático. Em resumo, a atuação externa do governo FHC pode ser descrita da seguinte forma, consoante à autora:

[...] por um lado, buscou-se reforçar a opção pelo fortalecimento das instituições multilaterais internacionais já que, por se auto definir como país intermediário com recursos limitados de poder, supunha-se que a adesão às normas de regulação internacional lhe garantiria a preservação de espaços de autonomia; por outro lado, devido à mesma auto percepção e ao fato de resgatar a condição do país de membro de um subsistema de poder da periferia, supunha-se que neste sua atuação devesse ser calcada em princípios de poder, garantindo-lhe por um lado maior autonomia e, por outro, maior respaldo no sistema global (PINHEIRO, 2004, p. 62-63).

Sob outra perspectiva, a política externa brasileira sob a chefia de Lula, novamente de modo sistemático e conciso, se caracteriza segundo Vizentini (2013) por:

[...] uma diplomacia econômica, outra política e um programa social. A primeira dimensão é realista, a segunda de resistência e afirmação e a terceira propositiva. Trata-se de um projeto amadurecido por mais de uma década, e não uma política voluntarista, e tem demonstrado estar adequada à correlação de forças existentes no país e no mundo (VIZENTINI, 2013, p. 112).

De forma mais ampla, Shiguenoli Miyamoto (2011), entende que a PEB de Lula pode ser sintetizados da seguinte forma: (I) a defesa dos interesses nacionais por meio da atuante diplomacia presidencial; (II) objetivando relevância no contexto internacional; (III) busca por cargos estratégicos em organizações internacionais; (IV) importância central na liderança regional, portanto, destaque para as relações vizinhas e sob o eixo da integração regional; (V) relações Sul-Sul, mormente as nações em desenvolvimento; (VI) alianças e aproximações internacionais pragmáticas, ou seja, sem distinção ideológica ou 
89 | InterAção

cultural; (VII) forte união com os emergentes, através do G3, G4, BRICS; (VIII) presença e atuação nos grandes temas globais, sobretudo nos temas caros ao desenvolvimento nacional, como o meio ambiente, a pobreza, e os recursos energéticos; (IX) atuação capaz como mediador de conflitos e ajuda internacional, como o caso do Haiti; (X) retórica proativa em relação aos problemas mundiais; (XI) modernização da Defesa Nacional (MIYAMOTO, 2011).

As particularidades centrais dessa política podem também ser articuladas por 4 ideias centrais que gerariam 7 pontos de intensidade maiores e lógicos, conforme Vigevani; Cepalunni (2007):

$\left(1^{\mathrm{a}}\right)$ contribuir para a busca de maior equilíbrio internacional, procurando atenuar unilateralismo; $\left(2^{\mathrm{a}}\right)$ fortalecer relações bilaterais e multilaterais de forma a aumentar o peso do país nas negociações políticas e econômicas internacionais; $\left(3^{\mathrm{a}}\right)$ adensas relações diplomáticas no sentido de aproveitar as possibilidades de maior intercâmbio econômico, financeiro, tecnológico, cultural etc.; e $\left(4^{\mathrm{a}}\right)$ evitar acordos que possam comprometer a longo prazo o desenvolvimento (VIGEVANI; CEPALUNNI, 2007, p. 291).

Examina-se ligeira interlocução com o entendimento anterior, porém de modo mais conciso. As ênfases que estes quatro pontos gerariam são as seguintes:

$\left(1^{\mathrm{a}}\right)$ aprofundamento da Comunidade Sul-americana de Nações (Casa); ( $\left.2^{\mathrm{a}}\right)$ intensificação das relações entre países emergentes como Índia, China, Rússia e África do Sul; $\left(3^{a}\right)$ ação de destaque na Rodada Doha e na Organização Mundial do Comércio, assim como em algumas outras negociações econômicas; $\left(4^{\mathrm{a}}\right)$ manutenção de relações de amizade e desenvolvimento das relações econômicas com os países ricos, inclusive com os Estados Unidos; $\left(5^{a}\right)$ retomada e estreitamento das relações com os países africanos; $\left(6^{\mathrm{a}}\right)$ campanha pela reforma do Conselho de Segurança das Nações Unidas, visando um lugar de membro permanente para o Brasil; e $\left(7^{\mathrm{a}}\right)$ defesa de objetivos sociais que 
90 | InterAção

permitiriam maior equilíbrio entre Estados e populações (VIGEVANI; CEPALUNNI, 2007, p. 292).

Esses distanciamentos e aproximações entre as políticas externas podem ser bem entendidas nas palavras de Vigevani; Cepaluni (2007), conforme o seguinte trecho:

[...] na nossa interpretação, ao mesmo tempo em que não houve ruptura significativa com paradigmas históricos da política externa do Brasil, sendo algumas das diretrizes desdobramentos e reforços de ações já em curso na administração FHC, houve uma significativa mudança nas ênfases dadas a certas opções abertas anteriormente à política externa brasileira. Consideramos ambos os governos (FHC e Lula da Silva) como representantes de tradições diplomáticas brasileiras distintas, apresentando diferenças nas ações, nas preferências e nas crenças, buscando resultados específicos muito distintos no que diz respeito à política externa, mas procurando não se afastar de um objetivo sempre perseguido: desenvolver economicamente o país, preservando, ao mesmo tempo, certa autonomia política (VIGEVANI; CEPALUNI, 2007, p. 275).

Observa-se, portanto, que mesmo duas políticas externas promovidas por gestões distintas e concorrentes, continham certos objetivos práticose bases conceituais comuns. Essa não ruptura de fundamentos históricos da PEB representa aqui parte do consenso desenvolvido ao longo desses governos. Nesse mesmo sentido, suscita Matias Spektor (2016): "o longo ciclo socialdemocrata sob asinsígnias PT-PSDB assistiu a um consenso fundacional entre as elites governistas" (SPEKTOR, 2016, p. 21). Do mesmo modo, ocorreu o consenso em outras esferas como a política econômica interna, a política social e a internacionalização das empresas nacionais. 
91 InterAção

\subsection{O FIM DO CONSENSO E AS PRIMEIRAS IMPRESSÕES DA PEB DE TEMER}

O consenso entrou em declínio e saturação a partir do governo Dilma Rousseff, especialmente após a quarta derrota presidencial consecutiva do PSDB. Sublinha-se que mesmo a economia demonstrando graves indícios de problemas, o Brasil encerrou 2014 com a menor taxa de desemprego da sua história ${ }^{2}$, e por outro lado, está vivendo o primeiro aumento no número de pessoas abaixo da linha de pobreza em uma década ${ }^{3}$. No entanto, não cabe aqui um debate mais robusto sobre os impactos econômicos oriundos da crise política induzida, do cenário internacional menos favorável, da queda de capacidade governamental e dos inúmeros casos de corrupção. Essa crise atingiu a autonomia e o desenvolvimento do país, resta saber em que níveis.

Ademais, esse momentocertamente marcará época na história nacional, o vice Presidente Michel Temer rompe abertamente após divulgação aberta de uma carta que expressava contrariedade aos caminhos do governo. "Desde então, Temer passou a trabalhar pelo impeachment, cujo processo fora acolhido pelo presidente da Câmara, Eduardo Cunha, alguns dias antes em resposta à recusa do PT em defendê-lo nas investigações. A aliança estava claramente desfeita" (REIS DA SILVA; SVARTMAN, 2016, p. 7). Além do mais, o PMDB apresentou e colocou em prática o programa Uma Ponte para o Futuro, programa com diretrizes opostas a chapa que o elegeu Vice e programa que não detém a legitimidade de escolha das urnas.

2 Disponível: http://g1.globo.com/jornal-da-globo/videos/t/edicoes/v/brasil-encerra-2014-com-a-menor-taxade-desemprego-ja-registrada/3928994/

${ }^{3}$ Disponível em: http://oglobo.globo.com/brasil/brasil-tera-ao-menos-25-milhoes-de-novos-pobres-ate-fim-doano-20915254 
92 | InterAção

No que tange a política externa, Charles Pennaforte (2016) estabelece dois rumos, quais sejam: "a primeira, o fim da atuação do Itamaraty na perspectiva autonômica em relação aos centros hegemônicos de poder. A segunda, está na dimensão comercial, ou seja, no pouco (ou inexistente) senso crítico sobre os parâmetros necessários para um país como o Brasil" (PENNAFORTE, 2016, p. 13). Já Reis da Silva; Svartman (2016) advertem a PEB de Temer no ponto em que "não é possível retornar aos anos 1990, período do otimismo liberal, a não ser na forma de farsa, o que seria uma tragédia para a inserção internacional soberana" (REIS DA SILVA; SVARTMAN, 2016, p. 11). E, dada essas expectativas preliminares, Marcelo Valença (2016), entende que a "primeira tendência que deve ser apontada á a provável redução do papel de protagonismo no que diz respeito à busca por liderança regional e internacional" (VALENÇA, 2016, p. 55). Além disso, a histórica pretensão de reforma do Conselho de Segurança das Nações Unidas “deve perder força, enquanto acordos comerciais bilaterais e no âmbito da OMC devem constituir a tônica da nova política externa" (VALENÇA, 2016, p. 56).

Em contrapartida, segundo Oliver Stuenkel (2017), a vitória de Donald Trump e seu comando AmericaFirst, estão se abrindo uma possibilidade de maior integração na américa latina a partir do recuo global e regional dos EUA. Assim, a possibilidade de maior integração "estaria em sintonia com um fenômeno global mais amplo. Como os Estados Unidos desempenharão um papel muito mais limitado tanto no plano econômico quanto no político, haverá mais espaço e necessidade de se fortalecer a cooperação regional" (STUENKEL, 2017) ${ }^{4}$. Portanto, apesar das grandes implicações internas que vinculam baixa legitimidade política e moral do governo em exercício, por sorte o cenário internacional pode vir a abrir uma brecha para manter ou voltar a acrescer autonomia e desenvolvimento. Pode, também, ser a grande saída para o

${ }^{4}$ Disponivel em: http://brasil.elpais.com/brasil/2017/02/13/opinion/1487024327_191535.html 
93 | InterAção

governo se manter até 2018 e procurar a desejada estabilidade política e econômica, em que pese os grandes retrocessos políticos e sociais em exercício e possivelmente a ser praticado pelo governo até as próximas eleições.

\section{CONSIDERAÇÕES FINAIS}

Resta demonstrado que o Brasil avançou e solidificou uma política externa assertiva e apropriada para as potencialidades do país durante os governos FHC e Lula, ainda que durante a gestão Dilma os traços de inserção externa tenham se mantido, o declínio qualitativo foi bastante evidente (CERVO; LESSA, 2014). Assim sendo, os governos FHC e Lula propiciaram um acréscimo de autonomia e de desenvolvimento nacionais a partir da política externa. Por meio de um consenso político capaz de exercer profundas mudanças positivas na vida econômica e social do brasileiro, conforme Matias Spektor (2016), "perdeu o atraso, ganhou o progresso" (SPEKTOR, 2016, p. 22). Nesse quadro geral e abrangente, o país de passos à frente, avançou, porém, logo em seguida estagnou e entrou em crise. Exemplo claro desse pêndulo brasileiro, a partir de uma visão de fora, é a matéria da revista The Economist de 14 de dezembro de 20095 em que o Brasil 'decolava' como uma legítima potência emergente; porém, meros quatro anos mais tarde a mesmo revista questionava o que teria ocorrido com o Brasil ${ }^{6}$.

A linha argumentativa empreendida no trabalho nos assessora para melhor compreender os avanços e os retrocessos da política externa brasileira no século XXI, desde os conceitos mais básicos às análises conjunturais atuais

\footnotetext{
${ }^{5}$ Disponível em: http://www.economist.com/node/14845197.

6 Disponível em: http://www.economist.com/news/leaders/21586833-stagnant-economy-bloated-state-andmass-protests-mean-dilma-rousseff-must-change-course-has.
} 
94 | InterAção

que infligem sobre as potencialidades nacionais. É preciso, em vias propositivas, encontrar saída para a estabilização econômica e política e, no quesito externo, as possibilidades devem girar em torno da ampliação da autonomia brasileira e não o seu decréscimo, da capacidade da política externa exercer atração em prol do desenvolvimento doméstico e não a sua dependência estagnação. Logo, o chamado entreguismo ou um alinhamento automático (por exemplo com os EUA) sem qualquer mecanismo de ganho ou barganha, não devem ser consolidados. Pois, como compreende Pecequilo (2008), existe uma "tradição das Relações Internacionais estadunidenses que demonstram que o país tradicionalmente beneficia parceiros com forte poder de barganha e não os que buscam alinhamentos" (PECEQUILO, 2008, p. 143).

Em derradeira, sublinhamos a necessidade de amparar-se em uma política externa condizente com as potencialidades, capacidades e necessidades do Brasil. O desafio é grande e o cenário interno é obtuso.

\section{REFERÊNCIAS}

ALMEIDA, Paulo Roberto. O Renascimento da Política Externa. Interesse Nacional. Ano 9, n. 34, Jul./Set. 2016.

ALMEIDA, Paulo Roberto. Entrevista. Política externa e diplomacia partidária no Brasil atual. InterAção. V. 6, n. 6, jan./jun. 2014.

AYRES PINTO, Danielle Jacon; BRAVO, Juliano dos Santos. A ação civil dos Estados Unidos no Golpe Civil-Militar brasileiro de 1964: uma perspectiva das Relações Internacionais. Editora Autografia: Rio de Janeiro, 2016.

AZAMBUJA, Marcos de. Política Externa e as Forças Políticas no Brasil.

Cadernos Adenauer XVII. N. 4. Rio de Janeiro, dezembro 2016. 
95 | InterAção

BRIGAGÃO, Clóvis; RODRIGUES, Gilberto M. A. Política Externa Brasileira: da independência aos desafios do século XXI. São Paulo: Moderna, 2006. [Cap. $1,2,7,8$ e 9$]$.

BUENO, Clodoaldo. Política Externa Brasileira em cenários de crises internas e externas. Brazilian Journal of International Relations. Marília, v.5, n.2, p. 277290, mai/ago 2016.

CERVO, Amado; LESSA, Antônio Carlos. O declínio: inserção internacional do Brasil (2011-2014). Rev. Bras. Polít. Inter. 57 (2): 133-151 [2014].

FLEMES, Daniel. O Brasil na iniciativa BRIC: soft balancing numa ordem global em mudança?. Revista brasileira depolítica internacional. vol. 53, №1, p. 141 156, julho 2010a.

FLEMES, Daniel. A visão brasileira da futura ordem global. Contexto Internacional - vol. 32, n. 2, julho/dezembro 2010 b.

FORMAN, J. M.; MYERS, E. Olhando para fora: o engajamento externo brasileiro após Dilma. Cadernos Adenauer XVII. N. 4. Rio de Janeiro, dezembro 2016.

GRABENDORFF, Wolf. Brasil: de colosso regional a potencia global. Nueva Sociedad. N. 226. Marzo-Abril 2010.

GUIMARÃES, Samuel Pinheiro. Inserção Internacional do Brasil. Economia e Sociedade. Campinas, (17): 1-31, dez. 2001.

HAKIN, Peter. O Brasil em ascensão: os desafios e as escolhas de uma potência global emergente. Política Externa. Vol. 19, n.1, jun/jul/ago 2010.

HIRST, Monica; LIMA, Maria Regina Soares de; PINHEIRO, Letícia. A Politica Externa Brasileira em tempos de novos horizontes e desafios. Análise de Conjuntura. OPSA. No 12, dez. 2010.

LUJÁN, Carlos A. Enlos bordes del poder mundial: Brasil a comienzos del siglo XXI. Revista Conjuntura Austral. Porto Alegre, v.7, n. 37, p. 52-66, ago/set. 2016.

MILANI, Carlos. Atlas da política externa brasileira. Ciudad Autonoma de Buenos Aires: CLACSO; Rio de Janeiro, EDUerj, 2014.

MIYAMOTO, Shiguenoli. A política externa brasileira em um contexto globalizado. Relações Internacionais no Mundo Atual. N. 9, p. 9-32, 2009-1. 
96 | InterAção

MIYAMOTO, Shiguenoli. A grandes linhas da política externa brasileira. Brasília: CEPAL e IPEA, 2011.

PECEQUILO, Cristina S. A Política Externa do Brasil no século XXI: os eixos combinados de cooperação horizontal e vertical. Rev. Bra. Polít. Int. 51 (2): 136153 [2008].

PENNAFORTE, Charles. A política externa brasileira em novos tempos: o fim da perspectiva ativa e altiva? VIII Congresso de Relaciones Internacionales. Universidad de La Plata, 23, 24 e 25 de noviembre de 2016.

PINHEIRO, Letícia. Política Externa Brasileira (1889-2002). Rio de Janeiro: Zahar, 2004.

PINO, Bruno Ayllón. Contribuiciones de Brasil aldesarrollo internacional: coaliciones emergentes y cooperaciónSur-Sur. Revista CIDOB

d'AfersInternacionals. N.97/98 (abril 2012), pp. 189-204.

SARAIVA, José Flávio Sombra. Autonomia na Inserção Internacional do Brasil: um caminho histórico próprio. Contexto Internacional. Rio de Janeiro. Vol. 36, n. 1, jan/jun. 2014, p. 9-41.

SARAIVA, Miriam Gomes. Balanço da política externa de Dilma Rousseff: perspectivas futuras? Relações Internacionais. Dezembro: 2014 [pp. 025-035].

SARAIVA, Miriam Gomes. A diplomacia brasileira e as visões sobre a inserção internacional do Brasil: institucionalistas pragmáticos x autonomistas. Mural Internacional. Ano 1. N.1. Jan/Jun. 2010.

SPEKTOR, Matias. Por uma nova doutrina de política externa brasileira.

Desafios da Política Externa Brasileira. CEBRI, 2016.

SPEKTOR, Matias. Diplomacia da transição. Folha de São Paulo. 29/10/2014.

Disponível em:

http://www1.folha.uol.com.br/colunas/matiasspektor/2014/10/1540019diplomacia-da-transicao.shtml

SVARTMAN, Eduardo M.; REIS DA SILVA, André L. Castigo sem crime? Raízes domésticas e implicações internacionais da crise brasileira. Revista Conjuntura Austral. Porto Alegre, v.7, n.35, p.4-14, abri/mar. 2016.

VALENÇA, Marcelo M. Política Externa Brasileira e Multilateralismo: o que esperar do novo governo. Cadernos Adenauer XVII. N. 4. Rio de Janeiro, dezembro 2016. 
$97 \mid$ InterAção

VELASCO JUNIOR, P. A. Uma América Latina em transformação: incertezas e possibilidades. Cadernos Adenauer XVII. N. 4. Rio de Janeiro, dezembro 2016.

VIGEVANI, Tullo; CEPALUNNI, Gabriel. A política externa de Lula da Silva: a estratégia da autonomia pela diversificação. Contexto Internacional. Rio de Janeiro, vol. 29, n², julho/dezembro 2007.

VIGEVANI, Tullo; OLIVEIRA, F. Marcelo. A política externa brasileira na era FHC: um exercício de autonomia pela integração. Tempo Social, São Paulo: Rev. De Sociologia da USP. Vol. 15. Nov. 2003 (2004).

VIZENTINI, Paulo Fagundes. Relações Internacionais do Brasil: de Vargas a Lula. Editora Fundação Perseu Abramo: São Paulo, 2005. [Cap. 1 e 4].

VISENTINI, Paulo Fagundes. Relações exteriores do Brasil II (1930-1964): o nacionalismo, da Era Vargas à Política Externa Independente. 2. Ed. Petrópolis, RJ: Vozes, 2009.

VISENTINI, Paulo Fagundes. A projeção internacional do Brasil (1930-2012): diplomacia, segurança e inserção na economia mundial. Rio de Janeiro: Elsevier, 2013. 